Correction

\title{
Correction to: Evaluation and calculation on the source of sulfur dioxide in waste gas of ceramic products manufacturing industry
}

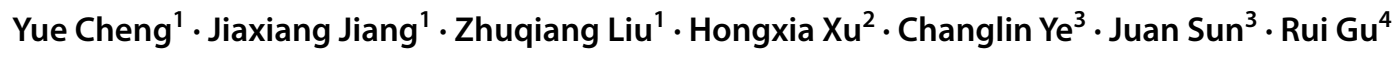

Published online: 27 July 2020

(c) Springer Nature Switzerland AG 2020

Correction to: SN Applied Sciences (2020) 2:1332

https://doi.org/10.1007/s42452-020-3033-4

The text of the original publication includes meaningless

characters in the following places:

- preceding the first sentence of Sect. 2.1

- the heading of Sect. 2.2.1, which should have read

\subsubsection{Content}

- the heading of Sect. 3.1, which should have read $\mathbf{3 . 1}$

Pre-stage results and analysis

Publisher's Note Springer Nature remains neutral with regard to jurisdictional claims in published maps and institutional affiliations.

The original article can be found online at https://doi.org/10.1007/s42452-020-3033-4.

$\triangle$ Yue Cheng, cy_jci@163.com | 'School of Materials Science and Engineering, Jingdezhen Ceramic Institute, Jingdezhen 333403, Jiangxi, China. ${ }^{2}$ Environmental Engineering Evaluation Center, Ministry of Ecology and Environment, Beijing 100035, China. ${ }^{3}$ Jiangxi Provincial Department of Ecology and Environment Environmental Engineering Assessment Center, Nanchang 330077, China. ${ }^{4}$ Jiangxi Ronghui Environmental Protection Technology Co., Ltd, Nanchang 330006, China. 